\title{
THE ISLE OF THE DEAD BENCHMARK, THE SYDNEY, FORT DENISON TIDE GAUGE AND THE IPCC AR5 CHAPTER 13 SEA LEVELS REVISITED
}

\author{
Albert PARKer \\ School of Engineering and Physical Science, James Cook University, Townsville, Australia
}

Manuscript received: July 22, 2014

Revised version: February 9, 2015

\begin{abstract}
PARKER A., 2015. The Isle of the Dead benchmark, the Sydney, Fort Denison tide gauge and the IPCC AR5 Chapter 13 Sea levels revisited. Quaestiones Geographicae 34(1), Bogucki Wydawnictwo Naukowe, Poznań, pp. 27-36, 1 fig. DOI 10.1515/quageo-2015-0003, ISSN 0137-477X.

AвSTRACT: The paper revisits the Isle of the Dead benchmark and the Sydney, Fort Denison tide gauge to confirm that long term, high quality tide gauges are acceleration free, consistently to the analysis of key sites suggesting the sea levels are not sharply raising following the carbon dioxide emissions. The paper also discusses the flaws of the IPCC AR5 Chapter13 Sea levels. The time history of the relative rate of rise computed by linear fitting of the data locally collected by tide gauges is the best parameter to assess the effect of global warming providing length and quality requirements are satisfied. There is no reason to search for less reliable alternative methods because the climate models predicted different trends. The Global Positioning System (GPS) inferred vertical tide gauge velocity suffers of significant inaccuracies. Larger inaccuracies are provided by the satellite altimetry Global Mean Sea Level (GMSL) that is a computation and not a measurement.
\end{abstract}

KEY WORDS: sea levels; tide gauges, key sites, ethics in science, scientific debate

Address of the author: Albert Parker, School of Engineering and Physical Science, James Cook University, Townsville, QLD, 4811, Australia, albertparker@y7mail.com

\section{Introduction}

The paper revisits the Isle of the Dead benchmark and the Sydney, Fort Denison tide gauge to confirm once more that long term high quality tide gauges are acceleration free, suggesting similarly to the analysis of key sites that the sea levels are not sharply raising following the carbon dioxide emissions. The relative rate of rise of sea level traditionally computed by linear fitting of the data locally collected by tide gauges, over a time span long enough and without gaps and measurement issues, is the best parameter to assess the effect of global warming. This procedure returns on average small rates of rise and zero time rates of change of these velocities. Key sites work similarly well. There is no reason to search for alternative methods simply because the climate models predicted different trends. The use of GPS to infer the vertical velocity of the tide gauge introduces significant inaccuracies, and the error in assessing absolute local rates of rise is still larger than the module of the trend. Even larger inaccuracies are provided by computations linked to the satellite altimetry, that is not an accurate measurement of the volume of the ocean waters, but only a computation not that different from the climate models. The Isle of the Dead benchmark and the Sydney, Fort Denison tide gauge, which have been the theatre of a battle between non-governmental and governmental climate scientists, are revised here. The flaws 
of the governmental claims about the Isle of the Dead benchmark and the Sydney, Fort Denison tide gauge and in the latest IPCC AR5 Chapter 13 on Sea levels (IPCC 2013) are shown in details.

\section{The Isle of the Dead benchmark}

A global key site is the sea level benchmark etched onto a cliff on the Isle of the Dead, Tasmania, Australia in 1841 by J.C.Ross (Daly 2003a, b). The benchmark was the theatre of Daly's last great battle with the climate science. Daly's uncovered flaws in the claims made by climate scientists that the Isle of the Dead mark was a proof of rapidly rising sea levels. The Ross benchmark currently stands more than $30 \mathrm{~cm}$ above present-day mean sea level. Ross in his account of his visit to Tasmania in 1841 stated clearly that the mark was struck at zero point or the mean level of the sea as he estimated it to be in 1841 (Ross 1847). Shortt (1889) found the mark to be $34 \mathrm{~cm}$ above Mean Sea Level (MSL). Hamon (1985) determined the MSL at Port Arthur to be $36 \mathrm{~cm}$ below the level of the benchmark with an error range of $\pm 5 \mathrm{~cm}$.

Not surprisingly, no matter what is written by Ross (1847), Shortt (1889) and Hamon (1985), Pugh et al. (2002) were able to publish in the peer review a paper arbitrarily correcting the benchmark location as originally set $44.5 \mathrm{~cm}$ above the mean level of the sea in 1841 rather than at the mean sea level, and omitting to consider not only the Ross (1847) narration, but also the assessments by Shortt (1889) and Hamon (1985) and any other information against their claim to conclude that the sea level risen $13 \mathrm{~cm}$ over 130 years mostly because the IPCC cannot be wrong.

Since Tasmania is geologically stable, the narratives by Ross (1847) and Shortt (1889) and the assessment by Hamon (1985) should better permit claims that there has been no rising sea, because the land uplift could not be used to explain why the benchmark is above the present mean level of the sea without significant variations over more than a century. However, Pugh et al. (2002) published their arbitrary revision of the past, while Daly $(2003 a, b)$ was not permitted to publish in the peer review his perfectly correct version of the story.

As a result of his climate activity, Daly (2003a, b) was targeted by efforts to destroy his repu- tation during his latest life and after he passed away. The animosity of the climate scientists vs. everybody not accepting their religious belief is evident in the comment by the Chief Scientist at Climatic Research Unit (University of East Anglia) Phil Jones on learning that J.Daly passed away, an astonishing ... in an odd way this is cheering news that does not deserve any comment (Watts 2009, Hockeyschtick 2009, Liveleak 2009). Before Daly (2003a, b), the work by Hamon (1985) was the most extensive and accurate research on the Ross benchmark. Hamon (1985) researched the benchmark before Pugh et al. (2002) published their paper during times where there was no need of a consensus science. Using the Hobart tide constants, Hamon determined the MSL at Port Arthur to be $36 \mathrm{~cm}$ below the level of the benchmark with an error range of $\pm 5 \mathrm{~cm}$, i.e. not only about same of the estimation proposed by Pugh et al. (2002) at $31.5 \mathrm{~cm}$, but also about same of the estimation at $34 \mathrm{~cm}$ by Shortt (1889) once the error bar is considered.

\section{The Hobart, Spring Bay and Sydney tide gauges}

The slow rising of the sea levels in the Isle of the Dead is confirmed when properly looking at the instrumental records of tide gauges. For Port Arthur, in front of the Isle of the Dead, the CSIRO (2013) tide gauge has been operating only a few years. Three years of data not help too much scientific assessment of long term trends dealing with signals characterised by multi-decadal oscillations up to quasi 60 years. There are longer tide gauge records located at Hobart to the northwest and Spring Bay to the north. Both tide gauges are less than the minimum $60-70$ years long. While the Hobart tide gauge is close to 60 years of recording even if with significant gaps, the Spring Bay tide gauge is less than 30 years old.

For a better understanding of the sea level pattern for the area, the closest long term tide gauge is Sydney, the oldest tide gauge of the Southern Hemisphere, covering the period January 1886 to December 2012 without any gap or other quality issue. The sea level is not expected to change too much between Hobart and Port Arthur because both harbours are adjacent to each other and both face south, while Spring Bay to the north is facing 
east toward the Tasman Sea and may present a different pattern.

For Sydney, the relative sea level velocity is computed from the data (PSMSL 2014) available for the two tide gauges sharing the Fort Denison location:

- PSMSL SYDNEY FORT DENISON (station 65, lat. -33.85 , long. 151.233333, coverage 1886 to 1993, completeness 100\%);

- PSMSL SYDNEY FORT DENISON II (station ID 196, lat. -33.85, long. 151.233333, coverage 1914 to 2012, completeness $98 \%$ ).

The absolute vertical velocity of the tide gauge may be guessed by the nearby GNSS station (SONEL 2014) of SYDN, with the relative motion tide gauges vs. nearby GPS dome unassessed.

For Hobart, the relative sea level velocity is computed from the data (PSMSL 2014) available for the two tide gauges:

- PSMSL HOBART (station ID 838, lat. -42.877328 , long. 147.340953, coverage metric data 1957 to 2012, completeness $80 \%$ );

- PSMSL HOBART II (station ID 964, lat. -42.9, long. 147.3, coverage metric data 1960 to 1990, completeness $74 \%$ ).

There is no nearby GNSS station (SONEL 2014) to assess the subsidence or isostasy rate nearby these tide gauges.

For Spring Bay, the relative sea level velocity is computed from the data (PSMSL 2014) available from different locations and tide gauges:

- PSMSL SPRING BAY (station ID 1216, GLOSS ID 56, lat. -42.545861, long. 147.932722, coverage RLR data 1992 to 2013, completeness $100 \%$, coverage metric data 1968 to 2013 , completeness $64 \%$ );

- PSMSL SPRING BAY II (station ID 1220, GLOSS ID 56, lat. -42.55, long. 147.933333, coverage metric data 1968 to 1989 , completeness $25 \%$ ).

The same GLOSS ID 56 is attributed to the SPRING BAY and the SPRING BAY II tide gauges.

For Spring Bay there is the nearby GNSS station SPBY from SONEL 2014 that however has a not robust record to assess the subsidence or isostasy rate nearby the tide gauges. The signal shows a more likely subsidence, but the signal is certainly not clear.

PSMSL (2014) proposes Revised Local Reference (RLR) and metric data. RLR means reduction to a common datum with a datum history, while metric refers to tide gauges not having the full benchmark datum history. Considering the many levelling issues and inaccuracies, the superior accuracy of the RLR data vs. the metric data purely speculative, and not only the metric data, but both the RLR and the metric data should be considered carefully.

The above data are provided to PSMSL (204) by the (Australian) National Tidal Centre (NTC). On their web site, the NTC proposes some complementary information (BOM 2014a, b). The Hobart tide gauges is owned by Tasmanian Ports Corporation, the Spring Bay tide gauge is owned by NTC and the Sydney (Fort Denison) tide gauge is owned by Sydney Ports Corporation. Therefore, two of the three tide gauges are managed independently by the NTC and not specifically operated to prove that global warming exists, while one tide gauge is mostly managed for the monitoring of global warming. The tide gauges of Sydney, Hobart and Spring Bay are analysed in figure 1 .

The composite tide gauge of Sydney (Fig. 1a to d), is obtained by coupling the two tide gauges of significant, successful overlapping 80 years long, exhibits an oscillatory behaviour about a $+0.652 \mathrm{~mm} \mathrm{yr}^{-1}$ slope linear trend line. Relevant are the multi-decadal oscillations of quasi-20 and quasi-60 years. The residuals about the fitting with a line and multiple sines do not show any sign of departures about the regular oscillatory behaviour since the 1990s.

The Sydney, Fort Denison tide gauge was the theatre of ones of A.A. Boretti's battle with the climate science. Boretti (2012b) stated the lack of any acceleration in the Sydney tide gauge also showing the claimed high rates of relative sea level rise computed by the Australian Baseline Sea Level Monitoring project (BOM 2014b) where only the result of multi-decadal oscillations.

Hunter, Brown (2013a) were permitted to comment the work by A.A.Boretti without the right-of-reply offered to the author of the original paper as it is standard procedure in the peer review when not dealing with the climate. The reply (Boretti 2013d) was only published as an arxiv paper. Boretti (2013d) was demonstrating that Hunter, Brown (2013a) possibly had a look at the paper, however without understanding too much of the contents, still misinterpreting the role of the phasing of the multi-decadal oscilla- 

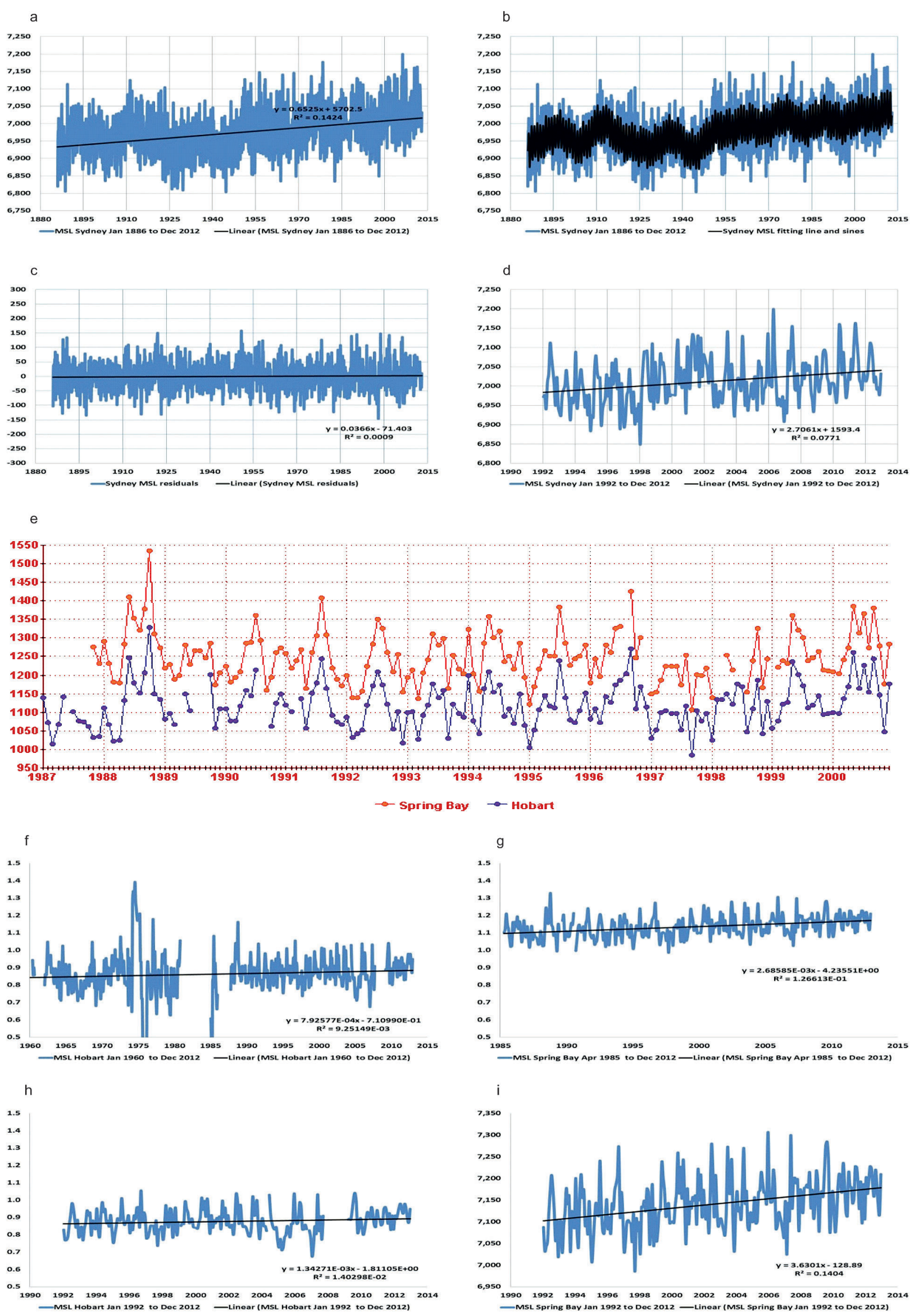

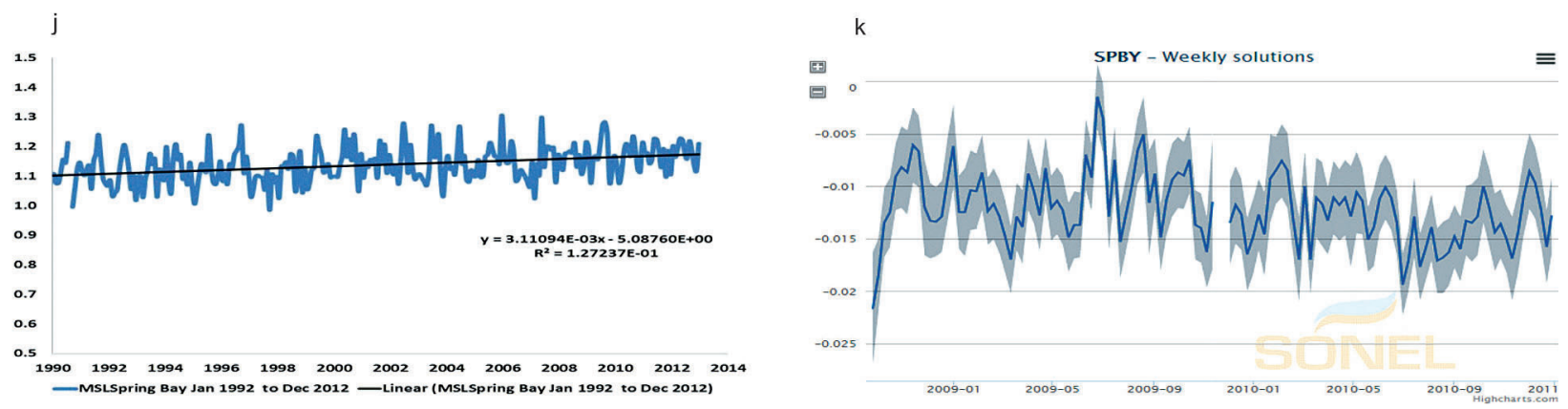

Fig. 1. Mean sea levels for different stations

a, b, c: Monthly average mean sea levels, their fitting with a line and sines, and the resulting residual in Sydney. These graphs are reproposed once more only because the climate scientists still fail to recognise that since the end of the 1800s the sea levels have been recorded by the tide gauges as naturally oscillating about a constant longer term trend of rise or fall with inter-annual and multi-decadal oscillation. Nor the line and sines fitting nor the measured data have accelerations

d: Monthly average mean sea levels in Sydney over the short time window Jan 1992 to Dec 2012

e: Monthly average mean sea levels in Hobart and Spring Bay as known in 2002 (Daly 2003a)

$\mathrm{f}$, g: Latest monthly average metric mean sea levels in Hobart and Spring Bay

h, i, j: Monthly average metric and RLR mean sea levels in Hobart and Spring Bay over the short time window Jan 1992 to Dec 2012

k: vertical velocity of the GPS dome nearby the Spring Bay tide gauges (SONEL, 2014). The information from the Tasmanian tide gauges of

Hobart and Spring Bay does not permit to infer any other conclusion if not Hobart has a relative rate of rise close to the one in Sydney while Spring Bay may have a larger relative rate of rise because of more subsidence and other biasing issues increased after the start of the Australian Baseline Sea Level Monitoring Project

tions. The work was also confirming the lack of acceleration worldwide average from the analysis of all the tide gauges of the Permanent Service on Mean Sea Level (PSMSL 2014) data base having enough quality and length to infer trends. The claim by Hunter, Brown (2013a) commenting Boretti (2012b) was only the result of the cherry picking the short time window to include the positive part of a multi-decadal oscillation.

The data January 1992 to December 2012 for Sydney show an apparent relative rate of rise of $+2.71 \mathrm{~mm} \mathrm{yr}^{-1}, 3.34$ times the legitimate value of $+0.65 \mathrm{~mm} \mathrm{yr}^{-1}$. However, this upwards motion already occurred in the past and will occur again in the future simply because it is part of a multi-decadal natural oscillation. The focus on the short time window is always wrong, but not surprisingly it shows opposite trends in different locations. While on the west side of the Pacific the Sydney tide gauge exhibits a positive phase over the last 2 decades, on the east side of the Pacific, the tide gauges of San Francisco, San Diego or Seattle exhibit a negative phase over the same time window.

By linearly fitting the data January 1889 to December 2013 for Seattle, the relative rate of rise is $+1.96 \mathrm{~mm} \mathrm{yr}^{-1}$. Over the short time windows January 1993 to December 2013, the apparent rate of rise is $-0.63 \mathrm{~mm} \mathrm{yr}^{-1}$ (negative).

By linearly fitting the data June 1854 to December 2013 for San Francisco, the relative rate of rise is $+1.41 \mathrm{~mm} \mathrm{yr}^{-1}$. Over the short time win- dows January 1993 to December 2013, the apparent rate of rise is $-0.94 \mathrm{~mm} \mathrm{yr}^{-1}$ (negative).

By linearly fitting the data January 1906 to December 2013 for San Diego, the relative rate of rise is $+2.05 \mathrm{~mm} \mathrm{yr}^{-1}$. Over the short time windows January 1993 to December 2013, the apparent rate of rise is $+1.41 \mathrm{~mm} \mathrm{yr}^{-1}$.

Nobody of the climate scientists only supporting the presence of hot spots of positive acceleration wrote a paper on the cold spots of negative accelerations along the West Coast of the United States, but if somewhere the sea levels oscillate up, somewhere else the sea levels oscillate down, and globally positive and negative oscillations cancel each other. For what concerns the vertical velocity of the tide gauge, the nearby GNSS station SYDN has a vertical velocity of $-0.89 \mathrm{~mm} \mathrm{yr}^{-1}$ (subsidence) subject to a significant accuracy error. The relative motion of the tide gauge is not measured, but very likely the relative sea level rise in Sydney is the result of the tide gauge moving down rather than the sea level going up. The absolute sea level velocity in Sydney is therefore very close to zero, exactly same conclusion from the narrative and assessments for the Ross benchmark.

The sea level time series for Hobart and Spring Bay from the data proposed by PSMSL in 2003 were showing no significant rate of rise over the time window 1987-1988 to 2001, with significant similarities between the two records (Fig. 1 e from Daly 2003a). The Spring Bay station is one of the few carefully selected baseline stations of the 
Australian Baseline Sea Level Monitoring (ABSLMP) project (BOM 2014b). The latest results for Spring Bay RLR are obtained with the novel SEAFRAME station installed 12/5/1991.

The ABSLMP project was proposed to substitute the measurements of the consolidated tide gauge network managed not only by the NTC but also by other independent bodies for many other purposes that not the sole assessment of the effects of climate change not providing the desired alarmist rates of rise of sea level. The consolidated data set was replaced by the few carefully selected baseline stations that all started their recording in a well-known valley of the peak and valley oscillations in the early 1990s. The short term ABSLMP stations were used to claim much higher rates of rise than those previously inferred from the analysis of the consolidated tide gauge network stations, that is clearly not the case (Mörner, Parker 2013, Parker et al. 2013).

The tide gauges of Hobart and Spring Bay (metric) over their record length (Fig. 1f, g) suggest relative rates of rise of $+0.79 \mathrm{~mm} \mathrm{yr}^{-1}$ and $+2.69 \mathrm{~mm} \mathrm{yr}^{-1}$ respectively. The different tide gauge lengths only partially explain the result. On the short time window January 1992 to December 2012, the Hobart tide gauge has a relative rate of rise $+1.34 \mathrm{~mm} \mathrm{yr}^{-1}$ vs. the $+0.79 \mathrm{~mm} \mathrm{yr}^{-1}$ of the longer time window, Figure 1.h, while the Spring Bay tide gauge has a relative rate of rise $+3.63 \mathrm{~mm} \mathrm{yr}^{-1}$ from the RLR data (Fig. 1i) and $+3.11 \mathrm{~mm} \mathrm{yr}^{-1}$ from the metric data (Fig. 1j). The higher relative rates of rise over the window January 1992 to December 2012 are not a surprise. Sydney (Fig. 1 a to d) clearly shows this is the effect of the phasing of the multi-decadal oscillations for this area of the South Pacific.

The long term relative rate of rise for Spring Bay is without any doubt much smaller than the +3.63 or $+3.11 \mathrm{~mm} \mathrm{yr}^{-1}$ suggested by the RLR or metric data. The vertical velocity of the GPS dome nearby the Spring Bay tide gauges is not assessed by SONEL, but the data suggest a much likely subsidence (Fig. $1 \mathrm{k}$ ). Without considering the very first results that makes the record not robust enough for SONEL, the subsidence rate is a substantial $5 \mathrm{~mm}$ over the 2 years' time window. The high rate of rise of the relative sea level in Spring Bay is very likely due to the short time window, subsidence at the tide gauge, and some massaging of the recorded data in equally significant portions. The relative sea level velocity in Sydney is very close to the subsidence velocity, for an absolute zero rate of rise. Hobart has a relative rate of rise similar to Sydney on the same time windows.

\section{Lack of ethics in the science of climate}

As evident from the many leaked climate-gate emails, it is common in the climate science that when an offending author publishes a paper questioning the consensus science of sharply rising temperatures and sea levels, public and private actions are then implemented against the offender to destroy the author reputation. It was the case of Daly, it was the case of Boretti.

Hunter, Brown (2013b) also misrepresented Boretti (2012b) in blogs. In the blog Hunter, Brown (2013b), the first sentence is Peer review prevents many, but not all, substandard articles from being published. Such failures are usually annoying but inconsequential, as poor quality articles are generally ignored. But when peer review fails on an article with contentious conclusions, this failure can be amplified by bloggers, the media and political campaigns. Alberto Boretti's paper on sea level rise near Sydney - which was published in the journal Coastal Engineering in June 2012 - is one such failure. This week, Coastal Engineering has published a commentary in which we discuss major flaws in Boretti's paper, some of which would be unacceptable in an undergraduate lab report. In another version of their blog, Hunter, Brown (2013c), the text is about the same, but now the picture of a monkey seating in front of a typing machine is used immediately below the title to graphically comment the activity of the offending author.

The blogs above certainly have nothing to do with science. Science is not about who is right and who is wrong because scientists should know that we all are wrong. Science is meant to allow debate about whatever subject and while doing that to make progress in knowledge. In science, the debate is about one scientist claim and opponents try to confute the claim and not to destroy the proponent. Other blogs by people with even less scientific credentials that Hunter, Brown (2013a, b, c) have been much worse than that. The major issue of global warming is that peoples without any formal education, knowl- 
edge or competence believe to have the right to be considered climate scientists and strong of this scientific knowledge, be authorised to personally defame the authors of scientific papers, that even if holding a PhD and a professorial position and be recognised as scientists by peers, suddenly are not scientists any more but only sceptics. This sort of approach has been a common practice of many totalitarian movements in the past, and unfortunately this is not the practice of the political and religious activists fighting for a new-world-order that will emerge from the destruction of the evil carbon.

The public activity was unfortunately only the emerged part of an iceberg made of unethical pressures on the editors of journals to further discredit the offending author and preventing further publishing, or the explicit requests to the managers of the offending author's to stop the politically incorrect activity.

\section{Flaws in the IPCC WGIAR5 Chapter13 Sea Level Change}

The latest IPCC WGIAR5 Chapter13 Sea Level Change is flawed as the claims about the Isle of the Dead and the Sydney, tide gauges. According to the authors The time-mean rate of GMSL rise during the 21st century is very likely to exceed the rate of 2.0 [1.7-2.3] mm $\mathrm{yr}^{-1}$ observed during 1971-2010, because the process-based GMSL projections indicate a significantly greater rate even under the RCP2.6 scenario, which has the lowest radiative forcing. In response to a reviewer's comment, it is then written It has been asserted that the acceleration of GMSL rise implied by the IPCC AR4 projections is inconsistent with the observed magnitude of acceleration during the 20th century (Boretti 2011, 2012a, b, c, 2013a, b, c, Boretti, Watson 2012, Parker 2013a, b, c). Refuting this argument, Hunter, Brown (2013) show that the acceleration projected in the AR4 is consistent with observations since 1990s. Present understanding of the contributions to GMSL rise (Section 13.3) gives an explanation of the rate of 20th century GMSL rise and confidence in the process-based projections, which indicate a greater rate of rise in the 21st century because of increasing forcing.

The works Boretti (2011, 2012a, b, c, 2013a, b, c), Boretti, Watson (2012) and Parker (2013a $b, c)$ were showing how the sea levels meas- ured by the tide gauges of enough quality and length were suggesting only oscillatory movements about same long term trend without any accelerating component on average over the last decades. Conversely, the IPCC AR5 Chapter 13 draft was proposing computational results of rising rates of rise. According to the final IPCC AR5 Chapter 13, the value of these works has been voided by the publishing of the single comment by Hunter, Brown (2013) that closes any further debate. The reply by Boretti (2013d) to Hunter, Brown (2013) it is not obviously cited, as not cited and the many other works published detailing the non-accelerating sea level pattern global and in every local geographical area. The $2 \mathrm{~mm} \mathrm{yr}^{-1}$ observed by the authors of the IPCC AR5 Chapter 13 during the period 1971-2010 do not have any support in actual measurements.

The 170 world tide gauges with more than 60 years of data in the PSMSL data base actually show a much smaller relative rate of rise, about $+0.403 \mathrm{~mm} \mathrm{yr}^{-1}$, constant over the period, very likely the result of more subsidence than isostasy at the tide gauge locations (Parker 2014c). This result is in sharp contrast to the global absolute rate of rise of about $3.2 \mathrm{~mm} \mathrm{yr}^{-1}$ since the 1990s claimed to be a satellite altimeter result. This result is however actually only another computation of no value, similarly to the many other climate model results, producing by assumption carbon dioxide emission-like trends for every tracked parameter.

The flaws of the IPCC AR5 Chapter 13 are linked to playing around three important aspects of sea levels measurements and computations.

The first aspect is that the oscillating behaviour of the sea levels, with many important periodicities of quasi-60 years and about 20 years detected in many areas, does not allow inferring any realistic trend if enough data of sufficient quality and length is not made available (Parker 2013b, c, d, e, 2014a, b, c, Parker et al. 2013, Parker, Watson 2013). Computation of trends by linear regression are unreliable when the tide gauge has been recording since less than $60-70$ years, when there are significant gaps in the tide gauge record, or when there are perturbing events in the recording making difficult the coupling of the data. Even with 60-70 years, the linear fitting of all the data will return a rate of rise that will be oscillating from one update to the other of the 
data set but in positive or negative depending on the local phase of the oscillations and representing nothing else if not the oscillations. By cherry picking the sea level record, it is equally possible to prove that the sea levels are sharply rising or sharply falling. However, these conclusions are equally wrong.

The second aspect is that a tide gauge measures the relative sea level, and the absolute vertical motion of the tide gauge is generally unknown or assessed with very poor accuracy (Parker 2014c). The velocity of nearby GPS domes is determined with accuracies still much larger than $\pm 1 \mathrm{~mm} \mathrm{yr}^{-1}$, as it immediately clear when comparing the velocities of the same domes computed by different groups, for example SONEL (2014) vs. JPL (2014). The uncertainty of the GPS dome velocity is larger than the relative sea level velocity module, and the relative motion of the tide gauge vs. the GPS dome is not measured to make the uncertainty even larger. This translates in the difficulty to determine with accuracy the local absolute rates of rise of sea levels. Therefore, rather than assessing the effects of global warming by computing the absolute rates of rise, it make much more sense to compute the time rate of change of the relative sea level velocity, i.e. the relative sea level acceleration (Parker 2013b, c, d, e, 2014a, b, c, Parker et al. 2013, Parker, Watson 2013) and to infer conclusion from this much better quality result. If the acceleration is not only not increasing, but also locally equally small positive and small negative and about zero on average in the compilations of tide gauges having sufficient worldwide coverage, quality and length, then the effect of global warming is without any doubt negligible.

The third point is that if the measure of the vertical velocity of a fixed point on land by the GPS, a global solution with millions of different uses and users is not that reliable, it is hard to believe that the satellite altimetry, a solution with few climate scientists as the only users, may produce a reliable and accurate measure of the instantaneous position of the continuously moving sea surface. The GMSL is actually a computational result obtained subjectively correcting a noisy, non-accurate, zero trend satellite altimeter result (Parker 2014c, Parker, Watson 2013). What produces a GMSL of $3.2 \mathrm{~mm} \mathrm{yr}^{-1}$ trend is only a computation, and the GMSL is therefore not different from the inaccurate and invalidated climate models (Parker, Watson 2013). The about $+0.403 \mathrm{~mm} \mathrm{yr}^{-1}$, constant, average relative rate of rise of the compilation of worldwide tide gauges of enough quality and length in the PSMSL data base (Parker 2014c) is a much more reliable result. Being the tide gauges of the compilation above mostly located in areas of more likely subsidence than isostasy as suggested by the GPS information when/where available (SONEL 2014, JPL 2014), the absolute rate of rise of sea levels is therefore very likely much closer to zero than the expected (Parker 2014c).

Another assessment of much better reliability than the GMSL is the addressing of global key sites (Mörner 2004, 2013). Consideration of sites having special importance like the Maldives, Bangladesh, Tuvalu, Kiribati and Vanuatu, or sites where the sea level rise can be easily tested like in Venice, the North Sea and French Guyana are indeed a very straightforward opportunity to test the accuracy of climate models predicting sea level rises of metres over a century. The Isle of the Dead benchmark may also be part of the list. At all these sites sea level seems to have remained stationary over the last 40-50 years (Mörner 2004, 2013).

\section{Conclusions}

Pugh et al. (2002) claim the Isle of the Dead benchmark was not struck at Mean Sea Level (MSL) as described by the man responsible for putting it there, Ross (1847), acting in association with Lempriere, but was rather struck closer to high tide. Thus, they claim the mark was $44.5 \mathrm{~cm}$ above MSL in 1841. Then they simply disregard the assessment by Shortt (1889) that the benchmark was 34 $\mathrm{cm}$ above MSL, and similarly they disregard the assessment by Hamon (1985) that the MSL was 36 $\mathrm{cm}$ below the level of the benchmark. They report the mark is now $31.5 \mathrm{~cm}$ above current MSL to put forward a wrong sea level rise of $44.5-31.5 \mathrm{~cm}=$ $13 \mathrm{~cm}$ since 1841 . The three assessments by Shortt (1889); Hamon (1985) and Pugh et al. (2002) actually show differences within the error bar over the 120 years. The zero absolute rise of sea level since the end of the 1800s is confirmed by the Sydney tide gauge instrumental record.

Hunter, Brown (2013) question the claim of Boretti (2012b) that the tide gauge of Sydney, 
Fort Denison is acceleration-free. Their analysis wrongly focuses on the latest positive oscillation of a multi-decadal natural movement disregarding the presence of the natural multi-decadal oscillations that influence the rate or rise of sea levels. Without cherry-picking procedures only selecting the time window or the tide gauge that supports positively accelerating sea level claims, there is not too much of positive acceleration measured by the Sydney tide gauge and the other tide gauges of the world of similar quality and length. The 170 world tide gauges with more than 60 years of data in the PSMSL data base presently show relative rate of rise of about $+0.403 \mathrm{~mm}$ $\mathrm{yr}^{-1}$, constant, very likely the result of more subsidence than isostasy at the tide gauge locations, for an average absolute rate of rise very close to zero (Parker 2014c).

The latest IPCC WGIAR5 Chapter13 Sea Level Change is flawed as the claims about the Isle of the Dead and the Sydney, tide gauge. The document suffers of major issues. The document provides a misinterpretation of the multi-decadal oscillations that make unreliable the use of short time windows in the analysis of tide gauge signals suggesting much larger or much smaller than legitimate relative rates of rise. The document overrates the reliability of absolute vs. relative rates of rise underestimating the accuracy issues in the measurements of the vertical land motion. Similarly, the document suggests as the ultimate measure of the absolute levels of the world oceans the satellite Global Mean Sea Level that is actually a computation, similar to the other climate models, only hypothetically based on the noisy, zero trended, satellite altimeter result.

If none of the tide gauges of enough quality and length of the world has acceleration, there is no reason why we should believe true the continuously accelerating reconstruction by the IPCC. If the average tide gauge of the world has a small relative velocity, and a close to zero absolute velocity, there is no reason why we should believe that the global absolute sea levels are rising of 3.2 $\mathrm{mm} \mathrm{yr}^{-1}$.

Climate scientists are very clever to correct past records or cherry picking the information in the direction of producing warming temperatures and rising seas. However, their ability to predict the future is very poor, as clearly demonstrated by the comparison of climate model predictions and measurements of temperatures and sea levels during this century. If the sea levels have to rise of 1 metre by 2100, we are still very far from these numbers. The average relative rise of sea levels has been $5.6 \mathrm{~cm}$ over the first 14 years of the century, at a constant rate, and it does not seem possible they could rise of other $94.4 \mathrm{~cm}$ over the remaining 96 years with the first sign of acceleration still missed.

\section{References}

BOM [Australian Government, Bureau of Meteorology], 2014a, Tide gauge metadata and observed monthly sea levels and statistics. Online: http://www.bom.gov.au/ oceanography/tides/monthly (accessed July 22, 2014). (accessed July 22, 2014).

BOM [Australian Government, Bureau of Meteorology], 2014b, Australian Baseline Sea Level Monitoring Project. Online: http://www.bom.gov.au/oceanography/ projects/abslmp/data/monthly.shtml (accessed July 22, 2014).

Boretti A.A., 2011, The measured rate of rise of sea levels is not increasing and climate models should be revised to match the experimental evidence. Royal Society Publishing eLetter, July 12, 2011.

Boretti A.A., 2012a, Short term comparison of climate model predictions and satellite altimeter measurements of sea levels. Coastal Engineering, 60: 319-322.

Boretti A.A., 2012b, Is there any support in the long term tide gauge data to the claims that parts of Sydney will be swamped by rising sea levels? Coastal Engineering, 64: 161-167.

Boretti A.A., 2012c, Discussion of Natalya N. Warner, Philippe E. Tissot, "Storm flooding sensitivity to sea level rise for Galveston Bay, Texas", Ocean Engineering 44 (2012), 23-32. Ocean Engineering, 55: 235-237.

Boretti A.A., 2013a, Discussion of Christine C. Shepard, Vera N. Agostini, Ben Gilmer, Tashya Allen, Jeff Stone, William Brooks and Michael W. Beck. Reply: Evaluating alternative future sea-level rise scenarios, Natural Hazards, 2012 doi:10.1007/s11069-012-0160-2. Natural Hazards, 65: 967-975.

Boretti A.A., 2013b, Discussion of J.A.G. Cooper, C. Lemckert, Extreme sea level rise and adaptation options for coastal resort cities: a qualitative assessment from the Gold Coast, Australia. Ocean and Coastal Management, 78: 132-135.

Boretti A.A., 2013c, Discussion of "Dynamic System Model to Predict Global Sea-Level Rise and Temperature Change" by Mustafa M. Aral, Jiabao Guan, and Biao Chang. Journal of Hydrologic Engineering, 18: 370-372.

Boretti A.A., 2013d, Reply to Hunter and Brown Discussion of Boretti Is there any support in the long term tide gauge data to the claims that parts of Sydney will be swamped by rising sea levels?, Coastal Engineering 2012;64: 161167, Coastal Engineering 2013;75:1-3". March 22, 2013. arxiv.org/abs/1303.5519

Boretti A.A., Watson T., 2012, The inconvenient truth: ocean Levels are not accelerating in Australia or over the world. Energy and Environment, 23: 801-817. 
CSIRO [Commonwealth Scientific and Industrial Research Organization], 2013, Historical Sea Level Changes, Last few hundred years. Online: http:/ / www.cmar.csiro.au/ sealevel/sl_hist_few_hundred.html (accessed July 22, 2014).

Daly J., 2003a, The Isle of the Dead part 1. Online: http:// www.john-daly.com/deadisle/ (accessed July 22, 2014).

Daly J., 2003b, The Isle of the Dead part 2. Online: http:// www.john-daly.com/deadisle/part2.htm. (accessed July 22, 2014).

Hamon B., 1985, Early Mean Sea Levels and Tides in Tasmania, Search 16(9-12): 274-277.

Hockeyschtick, 2009. climategate-in-odd-way-its-cheering. Online: http://hockeyschtick.blogspot.it/2009/12/climategate-in-odd-way-its-cheering.html (accessed July 22, 2014).

Hunter J.R., Brown M.J.I., 2013a, Discussion of Boretti, A., 'Is there any support in the long term tide gauge data to the claims that parts of Sydney will be swamped by rising sea levels?'. Coastal Engineering, 75: 1-3.

Hunter J.R., Brown M.J.I., 2013b, peer-review-isnt-perfectand-the-media-doesnt-always-help. Online: http://theconversation.edu.au/ peer-review-isnt-perfect-and-themedia-doesnt-always-help-11318 (accessed July 22, 2014).

Hunter J.R., Brown M.J.I., 2013c, peer-review-isnt-perfectand-the-media-doesnt-always-help/. Online: http:// world.edu/ peer-review-isnt-perfect-and-the-mediadoesnt-always-help/ (accessed July 22, 2014).

IPCC [Intergovernmental Panel on Climate Change], 2013, Fifth Assessment Report - Climate Change 2013 Chapter 13 - Sea levels. Online: http://www.climatechange2013.org/images/report/WG1AR5_Chapter13_ FINAL.pdf (accessed July 22, 2014).

JPL [Jet Propulsion Laboratory], 2014, GPS dome velocity data. Online: http:// sideshow.jpl.nasa.gov/post/series. html (accessed July 22, 2014).

Liveleak, 2009, In an odd way this is cheering news. Online: http:// www.liveleak.com/view?i=4b3_1259176479 (accessed July 22, 2014).

Mörner N.-A., 2004, Estimating future sea level changes from past records, Global and Planetary Change 40(1-2): 49-54.

Mörner N.-A., 2013, Sea level changes: past records and future expectations. Energy \& Environment 24 (3-4): 509-536.

Mörner N.-A., Parker A., 2013, Present-to-future sea level changes: The Australian case, Environmental Sciences: An Indian Journal, 8(2).

Parker A., 2013a, Comment to M Lichter and D Felsenstein, Assessing the costs of sea-level rise and extreme flooding at the local level: A GIS-based approach. Ocean and Coastal Management, 78: 138-142.
Parker A., 2013b, Sea level trends at locations of the United States with more than 100 years of recording. Natural Hazards, 65: 1011-1021.

Parker A., 2013c, Comment to Shepard, CC, Agostini, VN, Gilmer, B., Allen, T., Stone, J., Brooks, W., Beck, MW: Assessing future risk: quantifying the effects of sea level rise on storm surge risk for the southern shores of Long Island. Natural Hazards, 65: 977-980.

Parker A., 2013d, Oscillations of sea level rise along the Atlantic coast of North America north of Cape Hatteras, Natural Hazards, 65: 991-997.

Parker A., 2013e, Natural Oscillations And Trends In LongTerm Tide Gauge Records From The Pacific, Pattern Recognition in Physics, 1: 1-13.

Parker A., 2014a, Impacts of sea level rise on coastal planning in Norway, Ocean Engineering, 78: 124-130.

Parker A., 2014b, Present Contributions To Sea Level Rise By Thermal Expansion And Ice Melting And Implication On Coastal Management, Ocean and Coastal Management. Doi: 10.1016/j.ocecoaman.2014.05.026

Parker A., 2014c, Persisting problems affecting the reliability of the satellite altimeter based Global Mean Sea Level computation, Pattern Recognition in Physics.

Parker A., Saad Saleem M., Lawson M., 2013, Sea-Level Trend Analysis for Coastal Management, Ocean and Coastal Management, 73: 63-81.

Parker A., Watson T., 2013, Discussion of "Towards a global regionally varying allowance for sea-level rise" by J.R. Hunter, J.A. Church, N.J. White, X. Zhang [Ocean Engineering 71(1)17-27 (10 October 2013)], Ocean Engineering 72: $470-472$.

PSMSL [Permanent Service for Mean Sea Level], 2014, Monthly average relative mean sea levels. Online: http:/ / www. psmsl.org (accessed July 22, 2014).

Pugh D., Hunter J., Coleman R., Watson C., 2002, A Comparison of Historical and Recent sea Level Measurements at Port Arthur, Tasmania, International Hydrographic Review, 3(3): 27-45.

Ross J.C., 1847, A Voyage of Discovery and Research in the Southern and Antarctic Regions, During the Years 183943, John Murray, London, 22-32.

Shortt J., 1889, Notes on the Possible Oscillation of Levels of Land and Sea in Tasmania During Recent Years. Royal Society of Tasmania papers, State Library of Tasmania, Hobart: 18-20.

SONEL 2014, GPS dome velocity data. Online: http:/ / www. sonel.org (accessed July 22, 2014).

Watts A., 2009, breaking-news-story-hadley-cru-has-apparently-been-hacked-hundreds-of-files-released. Online: http:// wattsupwiththat.com/2009/11/19/ breakingnews-story-hadley-cru-has-apparently-been-hackedhundreds-of-files-released/ (accessed July 22, 2014). 